Área Abierta. Revista de comunicación

audiovisual y publicitaria

ISSN: 2530-7592 / ISSNe: 1578-8393

\title{
La construcción de identidades de género en la ficción audiovisual y sus implicaciones educativas
}

\author{
Patricia Martínez León ${ }^{1}$
}

Recibido: 5 de marzo de 2020 / Aceptado: 9 de agosto de 2020

Resumen. En este trabajo examinamos cómo obran los procesos de construcción de identidades de género, la socialización sexista y la violencia mediática en el discurso audiovisual. Recorremos el cambio de perspectiva resultante del diálogo entre feminismo y cine y realizamos una breve aproximación al estudio de la representación de la mujer en el discurso audiovisual. Finalmente, reflexionamos sobre las implicaciones educativas - en cuanto a la constitución del canon textual, la alfabetización mediática y la formación de lectores- de la formación de identidades genéricas en el audiovisual, con el propósito de sentar un punto de partida para la elaboración de propuestas didácticas que, desde el ámbito de la educación lectora, literaria y mediática, puedan contribuir a una construcción reflexiva de estas por parte de estudiantes adolescentes, en tanto receptores de esas ficciones audiovisuales que atraviesan una etapa de sus vidas en que los procesos de construcción identitaria se enfatizan.

Palabras clave: Identidad; Género; Educación Mediática; Educación Lectora; Feminismo; Cine

\section{[en] The Construction of Gender Identities in Audiovisual Fiction and its Educational Implications}

\begin{abstract}
We examine the processes of building gender identities, sexist socialisation and media violence in audiovisual media. We consider the change in perspective resulting from the dialogue between feminism and cinema and briefly approach the representation of women in audio-visual media. Finally, as a starting point for the preparation of teaching proposals, we reflect on the educational implications - in regard to the formation of the textual canon, media literacy, and reader training - of the formation of audiovisual gender identities. These teaching proposals contribute to reflective constructions by adolescent students - who are the recipients of these audiovisual fictions during a stage of their lives in which identity construction processes are emphasised - in the fields of reading, literature, and media education. Key words: Identity; Gender; Media Education; Reading Education; Feminism; Cinema
\end{abstract}

Sumario. 1. Introducción. 2. Socialización sexista y violencia mediática. 3. Construcción de identidades de género en el discurso audiovisual. 4. Un cambio de perspectiva: feminismo y cine 5 . A modo de conclusión. 6. Financiación. 7. Bibliografía.

Cómo citar. Martínez León, Patricia (2020). La construcción de identidades de género en la ficción audiovisual y sus implicaciones educativas. Área Abierta. Revista de comunicación audiovisual y publicitaria 20 (3), 317-333, http://dx.doi.org/10.5209/arab.68189

\footnotetext{
Universidad de Valencia, Grupo Elcis (España)

E-mail: patricia.martinez-leon@uv.es

ORCID: https://orcid.org/0000-0002-7269-5505
} 


\section{Introducción}

El papel de los medios de comunicación como agentes socializadores de primer orden, en tanto que construyen referentes y transmiten modelos, actitudes, valores y normas de conducta (Altés, 2012; Saneleuterio y López-García-Torres, 2018, 2019; Russo, 2019), la construcción de estereotipos de género y la sexualización de la mujer a través de estos (Gavilán, Martínez y Ayesterán, 2019) o el protagonismo de productos audiovisuales concretos, como puedan ser las ficciones seriadas, en la construcción identitaria de los más jóvenes (Cardona, Ferrer y Cifre, 2019; Parra, Postigo y Vera, 2019), han adquirido un creciente interés y han sido ampliamente estudiados en los últimos tiempos. Ya lo sostenía con tino Lomas (2007: 101):

Los textos de la cultura de masas — prensa, cómic, cine, televisión, publicidad, Internet, videojuegos - exhiben a gran escala ficciones, mitos y símbolos, héroes y heroínas, escenarios, escenas y argumentos, estereotipos y arquetipos, valores y creencias, relatos y contextos que influyen de una manera determinante en las ideas que sobre el mundo y sobre las personas adquirimos desde la más tierna infancia.

En la misma línea, no podemos olvidar, tal y como apunta Gago (2007: 113):

Cada época tiene, y trata de perpetuar, una concepción de género en función de su vida política, económica, cultural y social, que sirve de indicador capital de las características y funcionamiento de una sociedad. Para iniciar, desarrollar y apoyar la socialización de las nuevas generaciones en esta concepción y en sus consecuentes actitudes, responsabilidades y diferencias, cada sociedad y cada época se han valido de arquetipos, mitos, leyendas, cuentos y demás generadores de ideales colectivos, pues lo que, en último extremo, se persigue es crear un imaginario colectivo sobre lo que significa ser hombre y mujer en esa sociedad concreta en ese preciso momento.

O en palabras de Zurian, Martínez y Gómez (2015: 55):

Es bien sabido que los medios de comunicación proponen formas de construir la identidad de género, así como modelos representacionales de dicha identidad, de ahí que la forma de entender qué es masculino y femenino en esta sociedad eminentemente audiovisual responde a cierto modelo que se ofrece como canónico. La televisión no se escapa a esta tendencia, sino que de un modo todavía más incisivo crea dichos modelos canónicos, con tal fuerza, que llega, en algunos casos más sensibles - como entre los jóvenes y adolescentes - a convertirlos en prescriptivos y uno de sus recursos es ofrecer situaciones y comportamientos a través de los que sugerir escenarios o protagonistas que la audiencia interiorice a través del proceso de inmersión e identificación espectatorial. La ficción es siempre una modelización del universo real, incluso en el caso de los productos más fantásticos. De ahí que la ficción televisiva ofrezca modelos del mundo que luego pueden ser reinterpretados y significados por la audiencia.

Así, objeto de numerosas reflexiones y estudios recientes han sido, por ejemplo, la representación del mito del amor romántico en historias basadas en el sufrimiento 
y los celos y la naturalización de la desigualdad, la cosificación de niñas y mujeres y sus consecuencias en la salud mental de las receptoras (Bernal-Triviño, 2019), la devaluación de las mujeres mayores o la invisibilidad femenina en la ficción a partir de los cuarenta (Zecchi, 2014) o la persistencia de prejuicios, estereotipos y esquemas tradicionales de género, de una parte, y la proporción de modelos alternativos y el tratamiento novedoso de personajes femeninos en la literatura infantil y juvenil audiovisual y en el discurso fílmico en general, de otra (López González, 2019; Martínez y Merlino, 2012; Saneleuterio y López-García-Torres, 2018, 2019).

Para estudiar cómo construyen la imagen de la mujer los códigos de representación cinematográfica han sido distintas las opciones empleadas. Entre las modalidades de análisis más frecuentes se encuentran la semiótica, el análisis crítico del discurso, el psicoanálisis, la metodología estructuralista o la postestructuralista. Todo ello desde una perspectiva feminista que estudia funciones y representaciones de la mujer dentro de los textos que circulan en el marco de determinados contextos históricos, sociales e ideológicos.

En este trabajo nos interesan las implicaciones que para el ámbito educativo en general, y para la educación lectora, literaria y mediática en particular, posee la construcción de identidades genéricas en la recepción de la ficción audiovisual por parte de los jóvenes, pues pese a la impresión de una igualdad ilusoria en el sistema educativo, persisten las relaciones asimétricas entre chicos y chicas, la violencia de género, los proyectos y expectativas genéricamente diferenciados, la exclusión de las aportaciones de las mujeres de los contenidos y materiales curriculares o el sexismo (Flecha, 2014; García de Vicuña, 2018; Heredero de Pedro, 2019; Moriano, 2017; UNESCO, 2018).

Ello sigue haciendo necesaria la apuesta por una escuela coeducativa, que ayude a superar la asignación de papeles estereotipados y que elimine el sexismo, así como toda forma de discriminación negativa. Y esa escuela coeducativa, hoy día, no puede dar la espalda a los textos de la cultura de masas, convertidos en escenario preferente de los procesos de construcción identitaria de los más jóvenes. Una construcción que ha de ser necesariamente crítica, responsable y autónoma y que pasa por ejercicios como la detección de estereotipos o la identificación de intereses económicos e ideológicos subyacentes.

Y bien, sabemos que el sexismo, "el conjunto de todos y cada uno de los métodos empleados en el seno del patriarcado para poder mantener en situación de inferioridad, subordinación y explotación al sexo dominado: el femenino" (Sau, 2000: 257), traslada diferencias biológicas al plano sociocultural/ideológico y justifica un orden jerárquico que subordina a la mujer, imputando diferencias históricamente instituidas a una naturaleza biológica (García de León, 2011; Nash, 2003).

Estamos de acuerdo con Zurian, Martínez y Gómez (2015) en que en la creación de ficción, la simplificación de la realidad mediante la generalización de imágenes consensuadas y el uso de arquetipos es necesario para la construcción de personajes y para facilitar la identificación por parte del público y no desmerecemos la función narrativa que cumplen los estereotipos, pero también somos conscientes del relevante papel que juegan los medios en la difusión, uso y perpetuación o modificación de determinadas imágenes (Roca, 2005) y coincidimos con Gámez Fuentes (2009) en que, en particular, los estereotipos de género naturalizados en cuanto a lo que "tiene que ser" una mujer o un hombre nos instan a buscar pautas alternativas de configuración de imaginarios identitarios a través de nuevos patrones de representación. 
La construcción crítica de la identidad genérica que perseguimos pasa, a nuestro entender, por la formación de audiencias entendidas como creadoras activas, siguiendo a Barker (2003: 186-187), que "no aceptan sin más, de manera acrítica, los significados textuales, sino que hacen que sus competencias culturales influyan sobre estos".

Pues, indiscutiblemente "del hecho de que los textos construyan posiciones de sujeto no se sigue que todas las mujeres, o todos los hombres, acepten lo que se les ofrece; antes bien, los estudios acerca de la recepción han destacado las negociaciones entre el sujeto y el texto, incluida la posibilidad de resistencia a los significados textuales" (Barker, 2003: 182).

También Gámez Fuentes (2014) se referirá acertadamente, en este sentido, a las audiencias femeninas como agentes negociadores de los productos que consumen, entendiendo la relación de los sujetos con la producción cultural como una negociación y cuestionando así la supuesta unilateralidad del proceso de consumo cultural.

En esta línea, consideramos que la aportación del educador a esa construcción crítica pasa, no por la decisión, de antemano, de qué es bueno o malo, sino por la formación de receptores activos, con un intertexto lo más nutrido posible y por la constitución, en consecuencia, de un canon textual amplio y plural, en el que se incluya, por descontado, el texto audiovisual (Ballester e Ibarra, 2009, 2016; Marín, 2019). Obviamente, la configuración de cualquier canon lleva siempre implícito un ejercicio de poder en las inclusiones y exclusiones que su formación comporta, pero se le presume al docente en tanto profesional el compromiso con la calidad estética y narrativa, en primera instancia, y con la apuesta por una selección de autorías y representaciones identitarias lo más diversas posible, después, en aras de no limitar el desarrollo de ese sentido crítico esperable por parte de los estudiantes con su elección.

En las líneas que se suceden nos detenemos en cómo obran los procesos de construcción de identidades de género, la socialización sexista y la violencia mediática en el discurso audiovisual y en el cambio de perspectiva resultante del diálogo entre feminismo y cine, con el propósito de sentar un punto de partida para la elaboración de propuestas didácticas que, desde el ámbito de la educación lectora, literaria y mediática, puedan contribuir a una construcción reflexiva de las identidades genéricas por parte de los estudiantes, receptores de esas ficciones audiovisuales que atraviesan una etapa de sus vidas en que los procesos de construcción identitaria adquieren un énfasis especial.

\section{Socialización sexista y violencia mediática}

Por la importancia que tiene para nuestro trabajo empezaremos deteniéndonos en la categoría de género, definido como construcción sociocultural de la diferencia sexual que convierte esa diferencia en desigualdad, como una suerte de prescripciones que establecen lo propio de hombres y mujeres y que, en tanto que se presentan como naturales, constriñen las decisiones y los proyectos vitales de las personas.

Acompañar a Amorós (2000) en su recorrido por la definición aportada de la categoría de género a través de distintas autoras parece oportuno en este punto. De entrada, nos remite a Beauvoir, que define el concepto de género como una elaboración cultural, una suerte de traje o proyecto genérico hecho por y para alguien a 
la medida de unos determinados intereses. Según esta autora, solo en una sociedad con igualdad de oportunidades de realización existencial se disolverá la estructura de alteridad que convierte a la mujer en el otro. Más tarde Amorós nos conduce a Rubin, quien se referirá a la transformación de la sexualidad biológica en productos de la actividad humana y a la correspondencia entre sexo y naturaleza, género y cultura, que Butler criticará al cuestionar el carácter natural del sexo —a su juicio, también construido a través de dispositivos discursivos y de poder-.

Por su parte, Colaizzi (2007) define el género como tecnología — sujetos atravesados y estructurados por el poder y el lenguaje-, como construcción sociocultural y aparato semiótico - sistema de representaciones que atribuye significados a los individuos en la sociedad - y destaca la importancia de entender a la mujer como sujeto en proceso y múltiple, es decir, construido a partir de representaciones, relaciones y experiencias plurales, y de considerar en su seno una articulación de diferencias - clase, raza, preferencia sexual, religión, edad, etc.- irreductibles a la sexual.

Es en este trabajo, ante el establecimiento de una serie de imperativos de masculinidad y feminidad - recogidos en el cuadro 1-, pretendemos favorecer la atribución personal de significados por parte del alumnado en el diálogo o mediante la transgresión de lo establecido como normativo en materia de género, libres de la presión social que genera la constatación del cumplimiento de tales imperativos (Butler, 2004, 2006, 2010, 2015; Conway, Bourque y Scott, 2015; Lamas, 2015a, b, c).

\begin{tabular}{|l|l|}
\hline \multicolumn{1}{|c|}{ Imperativos de masculinidad } & \multicolumn{1}{|c|}{ Imperativos de feminidad } \\
\hline - Fuerza, agresividad, coraje. & - Debilidad, vulnerabilidad, pasividad. \\
- Autosuficiencia, independencia y confian- & - Necesidad de ser amada y deseo de ser \\
za en uno mismo. & protegida y cuidada. \\
- Éxito, capacidad adquisitiva y poder. & - Dependencia emocional, económica y psí- \\
- Heterosexualidad, derecho a disfrutar ple- & quica y falta de confianza en una misma. \\
namente de su sexualidad e invitación a & - Victimismo y depreciación de las propias \\
enorgullecerse de su promiscuidad. & habilidades. \\
& - Cosificación y atención excesiva a lo es- \\
& tético. \\
& - Valoración en función de su juventud y \\
& belleza. \\
& - Represión sexual y estigmatización social \\
& si disfruta de su sexualidad. \\
\hline
\end{tabular}

Imagen 1. Imperativos de masculinidad y feminidad.

[Fuente: elaboración propia a partir de la lectura de Herrera Gómez (2017)]

Huyendo de tales imperativos, coincidimos con Lomas (2007: 97-98) en que:

no existe una esencia arquetípica de lo femenino y de lo masculino sino un mosaico de identidades de género - heterogéneas y en ocasiones antagónicas - adscritas a uno u otro sexo. De ahí que en la mayoría de los estudios sobre la identidad femenina y masculina se tenga en cuenta que no existe una manera única y excluyente de ser mujer y de ser hombre sino mil y una maneras diversas de ser hombres y de ser mujeres. 
Conceptos asociados al de género que pueden resultar explicativos son los de identidad de género y roles de género. La primera, definida por Martínez Benlloch y Bonilla Campos (2000: 90) como "el resultado de un proceso evolutivo por el que se interiorizan las expectativas y normas sociales relativas al dimorfismo sexual, que hace referencia al sentido psicológico del individuo de ser varón o mujer con los comportamientos sociales y psicológicos que la sociedad designa como masculinos y femeninos".

Aquí parece interesante contraponer la noción de identidad feminista introducida por Amorós (2000: 81), que se referiría a "una forma crítico-reflexiva de ser mujer culturalmente constituida y modulada de formas diversas pero que tendría en común una desidentificación de los roles asignados y de los modos de heterodesignación impuestos".

Pasando al segundo de los conceptos, Martínez Benlloch y Bonilla Campos (2000: 91) definirán los roles de género como "un amplio repertorio comportamental y de valores que, desde la deseabilidad social, para cada cultura y momento histórico, delimitan el contenido de la masculinidad y la feminidad, siendo adquiridos a través de los mecanismos de control que pone en juego el proceso de socialización".

También de manera esclarecedora, Lamas $(2015 \mathrm{a}, \mathrm{b}, \mathrm{c})$ se refiere a tres instancias que se articulan en la categoría de género y que pueden ayudarnos a entender su desarrollo: la atribución de género al nacer a partir de la apariencia, el establecimiento de la identidad de género con la adquisición del lenguaje —que consiste en la identificación con determinados sentimientos, actitudes, etc.—y los roles de género como consecuencia de una socialización diferencial que se traduce en comportamientos "masculinos" o "femeninos".

En cuanto al desarrollo de la identidad genérica, igualmente Varela (2008: 182) explica con bastante claridad en las siguientes líneas cómo se produciría entre la infancia y la adolescencia:

depende, en el transcurso de la infancia, de la suma de todo aquello que los padres, los compañeros y la cultura en general consideran propio de cada género en lo concerniente al temperamento, al carácter, a los intereses, a la posición, a los méritos, a los gestos y a las expresiones. Cada momento de la vida del niño implica una serie de pautas acerca de cómo tiene que pensar o comportarse para satisfacer las exigencias inherentes al género. Durante la adolescencia se recrudecen los requerimientos de conformismo, desencadenando una crisis que suele templarse y aplacarse en la edad adulta.

En esta línea, como sostiene Acker (1995: 66-67), la socialización juega un papel muy importante:

las chicas - y los chicos — son socializadas — por la familia, la escuela, los medios de comunicación - en las actitudes y orientaciones tradicionales que limitan su futuro innecesariamente hacia ocupaciones y roles familiares sexualmente estereotipados. Al mismo tiempo, la socialización favorece los patrones de relación interpersonal entre sexos que ponen en desventaja a las mujeres, a las cuales se las sitúa en una posición de dependencia y respeto, y a los hombres se los empuja a reprimir sus potenciales emocionales. 
En este sentido, en la medida en que los medios de comunicación de masas se han convertido en un agente socializador de primer orden, no podemos obviar su incidencia en la construcción de las identidades genéricas. En el peor de los casos, en películas, series y anuncios publicitarios la mujer es cosificada, hipersexualizada y estereotipada — no podemos dejar de apuntar aquí, pese que no sea el objeto de este artículo, la objetificación y espectacularización también de la imagen masculina, de acuerdo, entre otros autores, con Mira, 2015- y, en el mejor, se cuestionan los modelos tradicionales de masculinidad y feminidad. En suma, ello da lugar a mensajes contradictorios sobre la base de los cuales los jóvenes construyen sus identidades.

Más allá de lo anterior, la aparición del denominado discurso postmachista genera confusión en torno a la persistencia de desigualdades en materia de género o a la existencia de la propia violencia machista. Y la instrumentalización del feminismo por parte de celebrities que incurren en la hipersexualización de sus cuerpos - convertida esta con frecuencia en requisito para entrar en la industria cultural- al tiempo que proclaman tópicos feministas muy superficiales convierte este movimiento en un producto mediático de consumo más y contribuye al aumento de la esquizofrenia social (Etura, Gutiérrez y Martín, 2017; Fernández Hernández, 2017; Fernández Rodríguez, 2017; Martínez Cano, 2017; Martínez y Aguado, 2017; Pibernat, 2017; Triviño, 2017).

En suma, la violencia mediática, que ha sido catalogada como un tipo de violencia simbólica, sirve para reforzar el mandato de género que instituye la desigualdad en sus múltiples formas - económica, social, política, cultural - y para legitimar otras violencias como la directa o la estructural (Bernal-Triviño, 2019; Moriano, 2017).

Evidentemente, desde el ámbito educativo y, en particular, desde la educación mediática, lectora y literaria, aspiramos a una construcción identitaria lo más autónoma posible por parte de nuestros estudiantes. En este trabajo consideramos, en consecuencia, que una recepción crítica de los contenidos mediáticos puede constituir una posible vía para la construcción reflexiva de las identidades genéricas por parte de los jóvenes.

\section{Construcción de identidades de género en el discurso audiovisual}

Cabe ahora que nos refiramos, en primera instancia, a los procesos de construcción identitaria y a las características y funciones que se les asocian para después detenernos en cómo se concretan dichos procesos en el discurso audiovisual. Y bien, después de la lectura de diferentes autores, destacaríamos cinco características de los procesos de construcción de identidades. Para empezar, se trata de un proceso eminentemente narrativo, es decir, somos - parcialmente - el resultado de los relatos que recibimos y elaboramos, de aquellos en los que nos reconocemos, de aquellos que nos aportan modelos para la identificación, así como de los que nos valemos para estructurar y conferir coherencia a la experiencia. Nuestra construcción identitaria es reflexiva en la medida en que existe - y si no existe habría que trabajar porque así fuera- un margen para nuestra participación activa a través de la recepción crítica de narraciones en distintos soportes. Plural porque la identidad es un concepto multidimensional — de género, sexual, cultural, profesional-, porque realizamos identificaciones múltiples y desarrollamos una diversidad de compromisos y sentidos de pertenencia compatibles a los que concedemos mayor o menor relevancia en función 
del contexto. Se trata también de un proceso dialógico, puesto que la identidad nunca es el resultado de un monólogo ni se corresponde sencillamente con la imagen que cada cual posee de sí mismo, sino que se desarrolla en la socialización, en la interacción, en el contraste y en el diálogo con otros. Y tiene, por último, un carácter proyectivo, que nos permite, de una parte, definir proyectos personales y colectivos con los que concedemos una dirección a la propia vida y asumimos responsabilidades sociales y, de otra, imaginar y aspirar a distintas posibilidades de ser y a otros mundos posibles (Berger y Luckmann, 1968; Giró Miranda, 2008; Rodríguez Lestegás, 2008; Susín Betrán y San Martín Segura, 2008; Valera y Madriz, 2005).

A la construcción de la identidad, como anticipábamos, se le asocian unas funciones. La primera sería la función locativa, puesto que la idea de identidad nos ayuda a ubicarnos, nos orientamos a veces basándonos en un determinado sentido de pertenencia. La identidad también tiene una función integrativa de las experiencias del pasado, del presente y del futuro, así como de las distintas imágenes que poseemos de nosotros mismos. Perceptiva, en la medida en que la pertenencia a determinadas comunidades incide en nuestro modo de ver e interpretar. $Y$ es una fuente de sentido, en tanto que nos aporta significados en los que nos reconocemos y somos reconocidos por otros (Guerrero Arias, 2002; Ruiz-Román, Calderón-Almendros y Torres-Moya, 2011).

Vayamos ya a la contextualización de esos procesos de construcción identitaria en el discurso audiovisual. Si consideramos el hecho fílmico como discurso cinematográfico hemos de tener necesariamente en cuenta la recepción que se realiza del texto audiovisual en contextos específicos y los efectos, afectos, reacciones, deseos o fantasías y posiciones subjetivas que produce en un espectador con una competencia lectora determinada, un intertexto y una determinada historia semiótica, personal y social, con una mayor o menor capacidad para reconocer el cine como instrumento no neutral, percibir su posible actuación como aparato ideológico — naturalización de valores hegemónicos y asignación de roles - y desentramar las relaciones históricas, económicas y sociales implicadas en la representación creada, pese a su apariencia de reflejo no mediatizado del mundo real (Colaizzi, 2001, 2007; De Lauretis, 1992; Kaplan, 1998; Kuhn, 1991).

Esta reflexión no solo es importante en sí misma sino también trasladable a los intereses de los estudios de género, pues, como sostiene Kaplan (1998: 42):

en el cine se traslada a la mujer, como tal, como mujer real, al segundo nivel de connotación, el mito; se la presenta como aquello que representa para el hombre, no por lo que verdaderamente significa. Su discurso - los significados que podría producir - se suprime en favor de un discurso estructurado por el patriarcado en el que se sustituye su significación real por connotaciones que satisfacen las necesidades del patriarcado.

La identificación con dichas representaciones, con modelos normalizados de feminidad y masculinidad y con papeles sexuales, que convierten a los sujetos en funcionales para una determinada estructura socioeconómica, juega un papel crucial en los procesos identitarios (Colaizzi, 2007; Mulvey, 1988). En este sentido, los códigos cinematográficos y también el atractivo de los personajes y de quienes los interpretan, las consecuencias narrativas de sus comportamientos o la excitación emocional generada por los recursos formales o los efectos sonoros refuerzan la 
identificación del espectador con el mundo ficcional. Y en la medida en que el espectador es interpelado por la película, se implica activamente y se compromete de manera subjetiva en el proceso de recepción y lectura, suma a sus identificaciones previas las que realiza en el texto fílmico (De Lauretis, 1992; Gago, 2007; Kuhn, 1991). Como sostiene Binimelis (2015: 10):

El cine refleja el funcionamiento y los discursos de la sociedad en la que surge, pero al mismo tiempo, tiene la capacidad de proyectar e influir en los comportamientos sociales, ya sea reproduciendo lógicas preexistentes o transformándolas. Así pues, como codificación discursiva, el cine recoge referencias a la realidad, tanto como la estructura y modifica. En palabras de Robert Stam: "A la 'textificación' del mundo le corresponde la 'mundificación' del texto”. En relación con esto, el modo en que la sociedad piensa sobre cuestiones de género está absolutamente mediatizado por los modelos de comportamiento y las actitudes que transmiten las películas. Estas pueden reproducir y consolidar desigualdades operantes en la sociedad. No obstante, también pueden generar discursos alternativos y transformadores con respecto a dichas relaciones de género. Partiendo, pues, de esta transposición mutua entre cine y sociedad, podemos considerar que la manera en que se tratan las cuestiones de género en el cine guarda cierta correlación con lo que ocurre más allá de la pantalla. Por ello, el estudio del cine se convierte en una poderosa herramienta para enfrentarse a esta problemática.

La propuesta de Gago (2007: 128-129) en las siguientes líneas de "aprender a ver el cine desde la escuela", entendiendo como tal la formación de esa audiencia activa a la que nos referíamos en la introducción, que pasa, en primera instancia, por la incorporación del texto fílmico al canon escolar, cobra ahora especial sentido:

Los aprendizajes sobre la identidad y el significado de los géneros por modelado simbólico a través del cine adquieren una especial relevancia: las consecuencias de las respuestas observadas en las películas actúan como elementos motivadores, incentivando y legitimando unos tipos de comportamiento y reprimiendo otros. Los alumnos y las alumnas, tras la visión de una película, generan imágenes mentales a partir de los discursos verbales y de los gestos faciales y corporales de los personajes, que pasan a formar parte de su imaginario sobre el tema. Estas imágenes recogen tanto aspectos positivos como negativos, pues el relato cinematográfico no ofrece — ni tiene por qué - códigos inapelables, sino perspectivas desde las que considerar los propios deseos y actuaciones: el espectador siempre completa y recrea, a su modo, la narración que le ofrece la pantalla. Por eso resulta imprescindible que se aprenda a ver el cine desde la escuela y también que se utilice, desde ella, para ayudar a ver lo que nos rodea y lo que nos preocupa en aspectos tan sustantivos como los relacionados con las concepciones sociales sobre los géneros.

\section{Un cambio de perspectiva: feminismo y cine}

Como sostienen Zurian y Herrero (2014), la teoría fílmica feminista es un marco teórico y metodológico especializado tanto en el análisis de la representación femenina 
en el audiovisual como en el de los géneros cinematográficos que ponen a la mujer en el centro de la narración.

Esta nos lleva a examinar el tratamiento de las mujeres en el discurso fílmico y a cuestionar la ideología sexista del cine hegemónico, a considerar las peculiaridades históricas, sociales, económicas e ideológicas subyacentes, a desnaturalizar modelos y representaciones, a entender las relaciones de poder que entran en juego en los procesos de construcción identitaria y, como diría Colaizzi (2007: 17), cuánto hay en juego en la imagen de la mujer:

Creo que una explicación del enorme interés de las feministas por la imagen y la profusión de textos que este interés ha generado puede encontrarse en la creciente conciencia de cuánto hay en juego en la imagen de la mujer y para las mujeres en un mundo dominado por los medios de comunicación de masas y la imagen, donde los estereotipos de feminidad constituyen a la vez un bien de consumo y un medio para promover el consumo.

La teoría feminista del cine, siguiendo a Kuhn (1991), se basa en gran medida en la noción de representación como construcción social e ideológica, mediatizada, que no refleja de manera inmediata el mundo o la sociedad reales y, en este sentido, asigna a la mujer una serie de significados y la convierte en el contenido de esos significados en los procesos de significación cinematográfica.

Ahora bien, más allá de la necesidad del cuestionamiento de los modelos hegemónicos - estereotipos de la chica buena frente a la chica mala, femme fatale, puta, madre o virgen, etc. - o de la búsqueda de modelos de mujer alternativos - fuertes, independientes, preocupadas por su propio placer sexual-, hay que destacar la importancia de reivindicar la posición activa y crítica del espectador o espectadora en el proceso de construcción de significado, que no necesariamente pasa por la identificación automática, por un único sentido o por usos sociales preestablecidos. Y habremos de considerar, además, la heterogeneidad de los espectadores y la pluralidad de interpretaciones posibles, reconociendo la distancia entre representación y realidad y contemplando también la función transformadora que puede tener la primera - más allá del reflejo, la reproducción o perpetuación de la desigualdad- y superar, como ya apuntara Johnston (1973, citada en Parrondo y González-Hortigüela, 2015), una visión monolítica de los medios como represivos y manipuladores.

Esta reivindicación engarza con el protagonismo concedido por la teoría feminista en la década de los ochenta al papel activo del espectador en la recepción fílmica, y con el interés focalizado en la interacción entre textos, espectadores, instituciones y entorno cultural, como apunta Binimelis (2015: 30):

El espectador ya no se concibe como una construcción singular del aparato ideológico, sino que se considera que las audiencias son múltiples. No hay un espectador masculino o femenino, sino individuos socioculturalmente diferenciados que hacen interpretaciones subjetivas de las películas. Se analiza el modo en que categorías como género, raza y clase afectan a la recepción y producen también significado.

Y bien, uno de los objetos de análisis más recurrentes han sido los estereotipos tradicionales de feminidad en el discurso fílmico - la mujer como objeto de deseo, 
adoración o violencia, sujeto pasivo o secundario carente de ambición, castigado cuando es activo, reducido a figuras complementarias y yuxtapuestas como madre/ femme fatale, virgen/puta y con la felicidad conyugal como sueño principal- (Colaizzi, 1995, 2007).

A juicio de Mulvey (1988) el éxito del cine clásico se basaría precisamente en el placer visual y sexual derivado de la conversión de la mujer en espectáculo y objeto de deseo. En ello conviene De Lauretis (1992: 13-14):

En el cine las apuestas por las mujeres son especialmente altas. La representación de la mujer como espectáculo - cuerpo para ser mirado, lugar de la sexualidad y objeto del deseo-, omnipresente en nuestra cultura, encuentra en el cine narrativo su expresión más compleja y su circulación más amplia.

Cabe hacer un inciso para anotar, no obstante, que tampoco le faltaba razón a Johnston (1973, citada en Parrondo y González-Hortigüela, 2015) cuando apuntaba al problema de la ausencia de un discurso de la mujer desde la perspectiva de la mujer y a la importancia de analizar la función que cumplen los personajes femeninos en los textos fílmicos, más allá de cómo son representados.

En cualquier caso, los primeros planos, el vestuario, el maquillaje, el escenario o la iluminación contribuirían a la conversión de la mujer en espectáculo y esta representación de la misma se examinaría para comprender sus efectos ideológicos en la construcción de los sujetos receptores y en el mantenimiento de las posiciones establecidas dentro de una cultura patriarcal.

En la actualidad, como resultado de las crecientes investigaciones desarrolladas desde la perspectiva de género en torno a una diversidad de productos audiovisuales - cine de animación, series, teen series, literatura infantil y juvenil audiovisual, etc.- se han podido identificar una serie de avances y de resistencias al cambio. Así, de una parte, se observa que algunos personajes femeninos representados en las ficciones audiovisuales son mujeres que se alejan de los convencionales estereotipos de belleza, de diferentes edades, trabajadoras, independientes, seguras e inteligentes, centradas en sus aspiraciones profesionales y exitosas en este terreno, además de sexualmente liberadas (Bonavitta y De Garay, 2019; Gutiérrez Martínez, 2019).

No obstante, de otra parte, este aire de renovación coexiste con algunas resistencias, como el mantenimiento de la figura de la femme fatal, del modelo de mujer dedicada al cuidado, con mayor dependencia emocional y necesidad de compañía que el hombre, al que idealiza y que continúa más sometida a los mandatos de belleza que este (Bonavitta y De Garay, 2019; Gavilán, Martínez y Ayestarán, 2019; Gutiérrez Martínez, 2019).

Además, se ha observado que, en ocasiones, aquellas mujeres que rompen arquetipos en las ficciones audiovisuales experimentan una soledad que no es mostrada como escogida y disfrutable, sino como vacía y triste, así como también cierta masculinización de los personajes femeninos con éxito profesional, que se hace corresponder con una suerte de "fracaso" en la vida de pareja (Bonavitta y De Garay, 2019).

En el análisis de las percepciones de las propias espectadoras como resultado de la recepción de estas ficciones audiovisuales - lo que resulta de especial interés en cuanto al estudio de la construcción de sus identidades genéricas-, se obtiene que notan y celebran avances tales como la introducción de nuevos temas y problemas 
abordados de una manera cercana y realista — nuevos modelos de familia y relaciones de pareja, diversidades sexuales, violencia de género, aborto, reproducción, maternidad y posparto, conciliación-, así como la mayor presencia y protagonismo de mujeres que responden a perfiles más complejos e interesantes o el desempeño por parte de estas de nuevos roles y su representación en una diversidad de contextos, pero continúan advirtiendo un desajuste entre lo representado en la ficción y las transformaciones sociales acontecidas en el mundo real, así como la persistencia de una sobrerrepresentación de la belleza, el consumismo, la dependencia emocional, las tareas del cuidado o la sexualización asociados en exclusiva a la mujer (Gavilán, Martínez y Ayestarán, 2019). Cabría hacer un estudio similar sobre los personajes femeninos en series de ficción dirigidas a espectadores jóvenes y sobre las percepciones de los mismos.

En cualquiera de los casos, sí es importante apuntar, en la línea de lo concluido por Zurian, Martínez y Gómez (2015: 61), que:

La ficción televisiva contemporánea, si bien no ha roto con los estereotipos de género ni se ha convertido en un vehículo de emancipación femenina o cuestionamiento de la masculinidad canónica patriarcal, sí estaría permitiendo la irrupción de nuevos discursos ficcionales que comienzan a socavar las bases androcéntricas y heteronormativas de los discursos mediáticos.

\section{A modo de conclusión}

No cabe duda de que los medios de comunicación son hoy día potentes plataformas de difusión de representaciones de género, como tampoco de su capacidad para propiciar la identificación por parte de los espectadores con las narrativas identitarias que ofrecen.

Pero no podemos perder de vista el papel activo del espectador en la creación de significados, que se identifica, cuestiona, se resiste a o lucha contra determinadas representaciones, en un ejercicio de negociación con el texto como lector competente.

Esto nos conduce a la necesidad de promover una alfabetización mediática crítica que forme a los estudiantes para posicionarse críticamente ante las representaciones y discursos procedentes de los medios, para leer, analizar y descodificar los textos mediáticos, para valorar su calidad estética y, por qué no, para aprender a usarlos también como vehículo de autoexpresión, creación y activismo social (Kellner, 2011).

En lo concerniente a esa construcción reflexiva de las identidades de género que consideramos un propósito deseable en este trabajo, al docente concernirá, además de esa alfabetización mediática crítica, la constitución de un canon textual que incluya ficciones audiovisuales que, sobre la base de la calidad estética, ofrezcan imaginarios y referencias genéricas plurales, aportando un catálogo lo más amplio posible de feminidades y masculinidades, ya normativas, ya transgresoras.

Desde el ámbito de una educación lectora, literaria y mediática, reconocida la contribución de las ficciones audiovisuales a la construcción de las identidades genéricas de los jóvenes y resueltos a apostar porque la institución escolar se convierta en puente hacia la cultura audiovisual, coincidimos con Zurian y Herrero (2014: 1819) en las siguientes palabras, que nos recuerdan, más allá de lo hasta aquí expuesto, 
la experiencia estética que la recepción de cualquier producto artístico habría de suponer, experiencia que consideramos que también nos concierne propiciar como docentes, junto a la formación de lectores críticos, constructores activos de significado en el diálogo con cualquier tipo de texto:

Proponemos, por lo tanto, un máximo respeto por el texto audiovisual, por el acercamiento a él y por su análisis, pero sin olvidarnos que puede contener, y de facto contiene, muchas implicaciones en la representación y en la construcción de identidades. El cine, el audiovisual, como cualquier artefacto cultural, es resultado de un espacio-tiempo determinado, realizado con una mentalidad y bajo unas condiciones también ideológicas, nunca neutrales, que construye un discurso del que se pueden desprender, y se desprenden de facto, modos de entender a la persona y su sociedad, su identidad y su ser. Y, por ello, también implicaciones en cómo se construyen y cómo se entienden las identidades de género y las cuestiones de sexualidad, cultura, raza, clase, etc. Porque todas estas cuestiones se entrelazan, son transversales, entretejen nuestra propia identidad. Pero que eso no nos impida ver la obra, que no nos impida la experiencia estética.

\section{Financiación}

Este trabajo se enmarca en el proyecto de investigación "Educación literaria, alfabetización multimodal y canon. UV-SFPIE Servei de Formació Permanent i Innovació Educativa PID 19-1098237”.

\section{Bibliografía}

Acker, S. (1995). Género y educación. Reflexiones sociológicas sobre mujeres, enseñanza y feminismo. Madrid: Narcea.

Altés, E. (2012). "La publicidad o la venta del imaginario oculto. ¿Existe violencia sexista en los anuncios?" Cuestiones de género: de la igualdad y la diferencia, núm. 7, 197-205.

Amorós, C. (2000). "Presentación (que intenta ser un esbozo de status questionis)". En Celia Amorós (ed.), Feminismo y filosofía. Madrid: Síntesis, 9-114.

Ballester, J. e Ibarra, N. (2009). "La enseñanza de la literatura y el pluralismo metodológico". Ocnos. Revista de estudios sobre lectura, núm. 5, 25-36.

Ballester, J. e Ibarra, N. (2016). "La educación lectora, literaria y el libro en la era digital". Revista Chilena de Literatura, núm. 94, 147-171.

Barker, C. (2003). Televisión, globalización e identidades culturales. Barcelona: Paidós.

Berger, P. y Luckmann, T. (1968). La construcción social de la realidad. Buenos Aires: Amorrortu.

Bernal-Triviño, A. (2019). "La concienciación de los medios sobre la violencia machista. Una interpretación por parte de sus víctimas". Revista Comunicación y Género, vol. 2, núm. 1, 15-31.

Binimelis, M. (2015). "Perspectivas teóricas en torno a la representación de las mujeres en el cine: una breve aproximación histórica". Secuencias, núm. 42, 9-34.

Bonavitta, P. y De Garay, J. (2019). "La casa de papel, Rita y Merlí: entre nuevas narrativas y viejos patriarcados". Investigaciones Feministas, vol. 10, núm. 2, 207-221. 
Butler, J. (2004). Lenguaje, poder e identidad. Madrid: Síntesis.

Butler, J. (2006). Deshacer el género. Barcelona: Paidós.

Butler, J. (2010). El género en disputa. El feminismo y la subversión de la identidad. Barcelona: Paidós.

Butler, J. (2015). "Variaciones sobre sexo y género: Beauvoir, Wittig y Foucault”. En Marta Lamas (comp.), El género: la construcción cultural de la diferencia sexual. México: Bonilla Artigas, 291-312.

Cardona, A. S., Ferrer, V. y Cifre, E. (2019). "El cine como agente socializador del amor romántico en las adolescentes: el caso de A tres metros sobre el cielo". Cuestiones de género: de la igualdad y la diferencia, núm. 14, 705-725.

Colaizzi, G. (1995). Introducción: Feminismo y teoría fílmica. En G. Colaizzi (ed.), Feminismo y teoría filmica (9-36). Valencia: Episteme.

Colaizzi, G. (2001). "El acto cinematográfico: género y texto fílmico”. Lectora, núm. 7, 5-13.

Colaizzi, G. (2007). La pasión del significante. Teoría de género y cultura visual. Madrid: Biblioteca Nueva.

Conway, J. K., Bourque, S. C. y Scott, J. W. (2015). “El concepto de género”. En Marta Lamas (comp.), El género: la construcción cultural de la diferencia sexual. México: Bonilla Artigas, 23-33.

De Lauretis, T. (1992). Alicia ya no. Feminismo, semiótica, cine. Madrid: Cátedra.

Etura, D., Gutiérrez, V. y Martín, V. (2017). "La cultura mediática y el discurso posmachista: análisis retórico de facebook ante la violencia de género". Revista de Investigaciones Feministas, vol. 8, núm. 2, 369-384.

Fernández Hernández, L. (2017). "El feminismo como producto mediático: la paradoja Beyoncé”. Revista de Investigaciones Feministas, vol. 8, núm. 2, 457-474.

Fernandez Rodriguez, I. (2017). "Entre ficciones y fantasías: el aprendizaje amoroso (y de género) a través del consumo cultural en la adolescencia". Revista de Investigaciones Feministas, vol. 8, núm. 2, 515-527.

Flecha, C. (2014). "Desequilibrios de género en educación en la España Contemporánea: causas, indicadores y consecuencias". AREAS. Revista Internacional de Ciencias Sociales, núm. 33, 49-60.

Gago, F. (2007). "Mujer y cine. El eterno femenino en el celuloide”. En Ana González y Carlos Lomas (coords.), Mujer y educación. Educar para la igualdad, educar desde la diferencia. Barcelona: Graó, 113-130.

Gámez Fuentes, M. J. (2009). “Conciliación, publicidad e infancia”. Asparkía, núm. 20, 81-98.

Gámez Fuentes, M. J. (2014). "Las mujeres en el cine y TV movies españoles (2000-2012): representaciones, sujetos y contextos". Historia y Comunicación Social, vol. 19, núm. Esp. Enero, 431-441.

García de León, M. A. (2011). Cabeza moderna/corazón patriarcal. Un diagnóstico social del género. Barcelona: Anthropos.

García de Vicuña, P. (2018). La desigualdad de género en la educación. El diario. Recuperado de https://www.eldiario.es/norte/vientodelnorte/desigualdad-genero-educacion_6 729737035.html

Gavilán, D., Martínez, G. y Ayestarán, R. (2019). "Las mujeres en las series de ficción: el punto de vista de las mujeres". Investigaciones Feministas, vol. 10, núm. 2, 367-384.

Giró Miranda, J. (2008). "La difícil construcción de la identidad entre los adolescentes hijos de la inmigración”. En Raúl Susín Betrán y David San Martín Segura (coords.), De identidades: reconocimiento y diferencia en la modernidad líquida. Valencia: Tirant lo Blanch, 275-315. 
Guerrero Arias, P. (2002). La cultura. Estrategias conceptuales para comprender la identidad, la diversidad, la alteridad y la diferencia. Quito: Ediciones Abya-Yala.

Gutiérrez Martínez, B. (2019). "Dialécticas de los personajes femeninos y masculinos en Mad Men: un análisis cuantitativo y cualitativo”. Investigaciones Feministas, vol. 10, núm. 2, 257-279.

Heredero de Pedro, C. (2019). Género y coeducación. Madrid: Morata.

Herrera Gómez, C. (2017). La construcción sociocultural del amor romántico. Madrid: Fundamentos.

Kaplan, E. A. (1998). Las mujeres y el cine. A ambos lados de la cámara. Madrid: Cátedra.

Kuhn, A. (1991). Cine de mujeres. Feminismo y cine. Madrid: Cátedra.

Lagarde, M. (1998). Identidad genérica y feminismo. Sevilla: Instituto Andaluz de la Mujer.

Lamas, M. (2015a). "Introducción”. En Marta Lamas (comp.), El género: la construcción cultural de la diferencia sexual. México: Bonilla Artigas, 11-21.

Lamas, M. (2015b). "La antropología feminista y la categoría de género". En Marta Lamas (comp.), El género: la construcción cultural de la diferencia sexual. México: Bonilla Artigas, 93-122.

Lamas, M. (2015c). “Usos, dificultades y posibilidades de la categoría de género". En Marta Lamas (comp.), El género: la construcción cultural de la diferencia sexual. México: Bonilla Artigas, 313-348.

Lomas, C. (2007). "El aprendizaje de las identidades femeninas y masculinas en la cultura de masas". En Ana González y Carlos Lomas (coords.), Mujer y educación. Educar para la igualdad, educar desde la diferencia. Barcelona: Graó, 95-112.

López González, R. C. (2019). "Cortos de animación en la red para todos los públicos y género: temáticas y roles de siempre contados como nunca". Revista Comunicación y Género, vol. 2, núm. 2, 249-265.

Marín, F. (2019). "La importancia de la cultura mediática en el ámbito de la educación literaria”. Campo Abierto, vol. 38, núm. 1, 75-88.

Martínez, P. y Aguado, D. (2017). "La reapropiación de los cuerpos de las mujeres en la ficción televisiva. Análisis de Orange is the New Black". Revista de Investigaciones Feministas, vol. 8, núm. 2, 401-413.

Martínez, A. y Merlino, A. (2012). "Normas de género en el discurso cinematográfico infantil: el eterno retorno del final feliz". Cuestiones de género: de la igualdad y la diferencia, núm. 7, 79-97.

Martínez Benlloch, I. y Bonilla Campos, A. (2000). Sistema sexo/género, identidades y construcción de la subjetividad. Valencia: Universitat de València.

Martínez Cano, S. (2017). "Las divas del pop y la identidad feminista: reivindicación, contradicción y consumo cultural". Revista de Investigaciones Feministas, vol. 8, núm. 2, 475-492.

Mira, A. (2015). “Mario Casas y el hombre 'depornosexual': la ‘espectacularización' erótica del cuerpo masculino". Área Abierta, vol. 15, núm. 1, 15-30.

Moriano, G. (2017). "Educación en igualdad de género para prevenir la violencia machista". Cuestiones de género: de la igualdad y la diferencia, núm. 12, 267-286.

Mulvey, L. (1988). Placer visual. Cine narrativo. Valencia: Fundación Instituto Shakespeare/ Instituto de Cine y RTV.

Nash, M. (2003). "Representaciones culturales y discurso de género, raza y clase en la construcción de la sociedad contemporánea”. En Mary Nash y Diana Marre (eds.), El desafío de la diferencia: representaciones culturales e identidades de género, raza y clase. Bilbao: Universidad de País Vasco, 21-35. 
Parra, P., Postigo, I. y Vera, T. (2019). "Resistencias y variaciones de la construcción del género en la nueva ficción seriada. Girls y Big Little Lies". Revista Comunicación y Género, vol. 2, núm. 2, 233-247.

Parrondo, E. y González-Hortigüela, T. (2015). "Releyendo a Laura Mulvey 40 años después. Historiografía y feminismo”. Secuencias, núm. 42, 53-72.

Pibernat, M. (2017). “¿Nuevas socializaciones, viejas cuestiones? Adolescencia y género en la era audiovisual”. Revista de Investigaciones Feministas, vol. 8, núm. 2, 529-544.

Kellner, D. (2011). Cultura mediática. Estudios culturales, identidad y política entre lo moderno y lo posmoderno. Madrid: Akal.

Rodríguez Lestegás, F. (2008). "Presentación”. En Francisco Rodríguez Lestegás (coord.), Identidad y ciudadanía. Reflexiones sobre la construcción de identidades. Barcelona: Horsori, 7-12.

Ruiz Román, C., Calderón-Almendros, I. y Torres-Moya, F. J. (2011). “Construir la identidad en los márgenes de la globalización: educación, participación y aprendizaje”. Cultura y Educación, vol. 23, núm. 4, 589-599.

Saneleuterio, E. y López-García-Torres, R. (2018). “Algunos personajes Disney en la formación infantil y juvenil: otro reparto de roles entre sexos es posible". Cuestiones de género: de la igualdad y la diferencia, núm. 13, 209-224.

Saneleuterio, E. y López-García-Torres, R. (2019). "Cuestiones de género y ciudadanía en el discurso fílmico". Revista Comunicación y Género, vol. 2, núm. 2, 147-159.

Quintana, B. (2019). "La articulación política feminista desde la comunidad. Análisis interseccional de Las escalofriantes aventuras de Sabrina". Investigaciones Feministas, vol. 10, núm. 2, 333-350.

Roca, M. (2005). "Uso y abuso de la estereotipia en los medios de comunicación. Propuestas para un consumo sostenible desde la perspectiva de género". Área Abierta, núm. $12,1-6$.

Russo, M. (2019). "Devolver la mirada: el personaje de Vera en La piel que habito de Pedro Almodóvar". Revista Comunicación y Género, vol. 2, núm. 2, 161-182.

Sau, V. (2000). Reflexiones feministas para principios de siglo. Madrid: Horas y horas.

Susín Betrán, R. y San Martín Segura, D. (2008). “A modo de presentación”. En Raúl Susín Betrán y David San Martín Segura (coords.), De identidades: reconocimiento y diferencia en la modernidad líquida. Valencia: Tirant lo Blanch, 17-33.

Triviño, L. (2017). "Feminismos, postmodernidad y cultura mediática en las aulas: el videoclip pop estadounidense como herramienta educativa para la discusión de temas controversiales". Revista de Investigaciones Feministas, vol. 8, núm. 2, 493-514.

UNESCO (2018). Resumen sobre género del informe de seguimiento de la educación en el mundo. Cumplir nuestros compromisos de igualdad de género en la educación. París: Organización de las Naciones Unidas para la Educación, la Ciencia y la Cultura.

Valera, G. y Madriz, G. (2005). "Las letras en el tejido de la vida. Literatura del yo y educación”. En Jorge Larrosa y Carlos Skliar (coords.), Entre pedagogía y literatura. Argentina: Miño y Dávila, 201-219.

Varela, N. (2008). Feminismo para principiantes. Barcelona: Ediciones B.

Villoro, L. (1998). Sobre la identidad de los pueblos. Estado plural. Pluralidad de culturas. México: UNAM/Paidós.

Zecchi, B. (2014). La pantalla sexuada. Madrid: Cátedra.

Zurian, F. A. y Herrero, B. (2014). "Los estudios de género y la teoría fílmica feminista como marco teórico y metodológico para la investigación en cultura audiovisual". Área Abierta, vol. 14, núm. 3, 6-21. 
Zurian, F. A., Martínez, D. y Gómez Hernando, C. (2015). "La ficción en la televisión generalista norteamericana y la representación de (nuevas) masculinidades". Área Abierta, vol. 15, núm. 1, 53-62. 